\title{
Research on Governance Mode Development of the State-Owned Enterprise: A Framework on the Theory of Principal-Agent
}

\author{
Ying $\mathrm{CHEN}^{1, \mathrm{a}}$ and Qiu-ming $\mathrm{WU}^{2, \mathrm{~b}}$ \\ ${ }^{1}$ Fu Zhou University, China, ${ }^{2} \mathrm{Fu}$ Zhou University, China \\ a602042290@qq.com, bqiuming30@sina.com
}

Keywords: Governance mode, State-owned enterprise, Principal-agent.

\begin{abstract}
With the state-owned enterprise reforming, state-owned enterprise governance mode had experienced a series of changes, the principal-agent relationship in different periods show different characteristics. This paper analyzes the characteristics of the governance mode of state-owned enterprise during the beginning of reform and opening up including the "decentralization" stage and responsibility system stage, stage of establishing modern enterprise system on the Principal-Agent Theory. The conditions for the optimal solution of the principal agent and the agent are revealed by the method of solving the equation. The relationship of the principal-agent relationship in each stage is analyzed, and the development process of the governance model of the state-owned enterprise is sorted out, providing a useful reference for the further reform in the governance mode of the state-owned enterprises.
\end{abstract}

\section{Introduction}

After more than 30 years of reform, China's state-owned enterprises have made progress and achievements in the aspects of organization structure, system reform, and management innovation and so on. 2014, state-owned enterprises realized a total profit of 24765.4 billion $\mathrm{RMB}$, an increase of 3.4\%. Among them, the central enterprises have 17280.2 billion RMB, an increase of $3.6 \%$; the local state-owned enterprises have 7485.2 billion RMB, an increase of $2.8 \%$. State-owned enterprises have experienced three periods of the planned economy period, the initial stage of reform and the economic transformation. The reform of each period has obvious characteristics of the times. Especially after the reform and opening up, the reform has been the main theme of the state-owned enterprises. The governance mode of the state-owned enterprises has undergone a series of reforms in the institutional changes of China's state-owned enterprises, from the Contracting System or Share-Holding System in 1979, to the Responsibility Contract System in 1986, and then to the establishment of the modern enterprise system.

The core of the governance model is the establishment of the principal-agent relationship, the essence of which is a kind of contractual relationship. The core of this contractual relationship is the distribution of the residual value between the principal and the agent, and the method of dealing with this kind of relationship is to establish incentive compatibility mechanismbetween the owners and managers. In the planned economy era in China, there is no principal-agent relationship due to the owner and manager is the one. With the reform and opening up in the "decentralization" reform, China's state-owned enterprise ownership and management right started to separate, and the principal-agent relationship began to form. And because of the diversity of the nature of the state-owned enterprises, the principal-agent 
relationship is more hierarchical and complex than the ordinary private enterprises. In this paper, the state-owned enterprise ownership and management rights gradually separated after the reform and opening up, each stage of the governance model with the principal-agent theory analysis, the characteristics of each phase of governance model, the existing problems and policy implications of the research, combing the development of state-owned enterprise governance model, the current state-owned enterprise reform to provide useful reference.

\section{The Governance Model in Early Stage of Reform}

Before the reform and opening up, the state-owned enterprises are completely in the bi-power unison. The state has all the decision-making power, completely does not participate in the market competition, the state-owned enterprise's production efficiency is low, the production enthusiasm is not high. Therefore, the country began a series of reforms of state-owned enterprises from the 1978; the first stage is the "decentralization" to "responsibility system stage". Through these reforms, the governance mechanism of state-owned enterprises from scratches, and presents a unique feature.

\section{The General Situation}

\section{Decentralization and Tax Stage}

This stage through a series of reform measures, given the state-owned enterprises a certain autonomy and the remaining profits of the control. The main policy includes "decentralization and interest concession", "substitution of tax payment for profit delivery" and "government financing", these policies make state-owned enterprises has become the enterprise legal person has certain rights and obligations, to a certain extent, to expand the autonomy of enterprises. These reforms are mainly reflected in the following two aspects in governance model of the state-owned enterprise:

First, there are some changes in the distribution of decision-making power of the governance model. "Decentralization" and a series of policies give state-owned enterprises a profit control, production and operation of power and some bonus distribution rights, from a certain extent changed the distribution of the original state-owned enterprise decision-making. However, this reform has not touched the basic institutional framework of state-owned enterprises; all the reform measures are floating on the surface. The status of state-owned enterprises is still the government's appendages, the power of employment, investment, pricing, and so is still firmly in the hands of the government departments. Therefore, there is no "agent" in the governance model of state-owned enterprises in this period in real meaning.

Second, there are some changes in the profit distribution mode of governance model. Substitution of tax payment for profit delivery to make the relationship between state-owned enterprises and the state become an independent production and business units to pay taxes to the state, rather than the original use of a certain percentage of profits between the enterprise and state, using the tax law to regulate the distribution of profits between the state and state-owned enterprises. From this point of view, this reform has made significant progress and effect compared with the past method of tax reform.

\section{Contract Responsibility System Stage}

Although the reduction of the administrative constraint of state-owned enterprises to a certain extent, mobilize the enthusiasm of the state-owned enterprises, but the law and economic constraints are not kept up with. And the information asymmetry between the government and 
state-owned enterprises, there is a phenomenon of wage erosion profit and whipped fast and hard working. In order to ensure that the interests of the state are not eroded and further transform the operating mechanism of the state-owned enterprises, the state has also put forward the reform measures to implement the contract responsibility system. This policy provides state-owned enterprises to determine a certain amount of base. Pay a fixed base at the end of the year, if the profit more than the base, the enterprise can keep; but if not up to the base, enterprise should complete. The impact of this policy on the governance model of state-owned enterprises is mainly reflected in the following two aspects:

First, there are some changes in leading role orientation. Before the reform, state-owned enterprises are responsible for the factory director. But the director is under the leadership of the Party committee, which is essentially the highest authority. The power of the director is without foundation who is only the performer without any real power. After the implementation of the contract responsibility system, the leadership role of the director has also changed with the independent authority has been delegated. The director has the right to operate and management, and has become the power center of the organization and management, the role of the Party committee to support and assist the director of business decisions.

Second, there are some changes in the profit distribution mode. Before the reform, the profits of state-owned enterprises are all given to the country; the wages of the managers are paid by the state. After the implementation of the contract responsibility system, the share of the profits of the state-owned enterprises is determined by the state and the enterprises, the manager's salary is allocated by the post of the surplus of the balance. Managers' pay level to some extent with their labor pay and corporate performance management, so that the enthusiasm of state-owned enterprises have also been greatly improved.

\section{Analysis Based on Principal-Agent Theory}

This stage has a remarkable characteristic of the reform of the governance model, which is "Insider Control" under the administrative intervention. In the management there is lacking of "Principal" in fact. "Agent" is in the distribution of profits, in the pursuit of maximizing their own profit, on the one hand, state-owned enterprises to improve the production efficiency, on the one hand and using illegal means of misappropriation of state assets.

\section{The Principal-Agent Relationship in Contract Responsibility System}

In the contract responsibility system, the state-owned enterprises should pay a certain fixed base of the profits to the state, and the rest of the profits can be free. The principal-agent relationship under this system, $\chi=$ Total Income, $r=$ Expense, ${ }{ }_{0}=$ Satisfactory profit. Agent has become holder when $\chi \geq r+\pi_{0}$; the agent is not the owner of the enterprise when $\chi<r+\pi_{0}$. But because of the information asymmetry between the government and the state-owned enterprises, the lack of a perfect and effective supervision system, the government assessment of state-owned enterprises at the end of the year, the state-owned enterprises even if not complete the corresponding profit base, they can also through the "Cook Accounts" and other means to fictitious profits or to explain why not meet the relevant indicators, which is also an economist in the study of soft budget constraints. Therefore, in either case, the agent is the so-called "holder", the government has become a decoration in the principal-agent relationship, and there is no substantive role. 


\section{Incentive-Constrain Mechanism in Contract Responsibility System}

The principal-agent relationship in the contract responsibility system is different from the planned economy era in nature. In the planned economy era, the objective function of the agent is the fixed output under the specific production function, the utility of whom is not tied to the output, whose salary is amount number. So in this case, the attitude of the agent to the risk is obviously to avoid. In the contract, the contractor may participate in the distribution of profits, so they in order to maximize their objective function, will have a greater incentive to pursue profits. Different from the planned economic period, they have a neutral attitude towards risk. Under the condition of symmetric information, the principal-agent relationship of state-owned enterprises under the contract responsibility system is analyzed.

The profit function:

$$
\pi=\pi(\gamma, \alpha, \tau)
$$

Among them, $\pi$ =Profit; $\gamma=$ Agent's efforts; $\alpha=$ Parameter (If the agent has the power to make the decision). Agent has no decision-making power when $\alpha=0$; the agent has the right to make the decision when $\alpha=1 ; \tau$ is natural state. In addition, this paper assumes that $\pi$ is a monotonically increasing function of $\gamma$ and $\alpha$, and $\tau$ is an increasing function. The profit distribution between the government and the contract enterprise is as follows:

$$
\begin{aligned}
& y_{C}=\pi_{1}+R\left(\pi-\pi_{0}-\pi_{1}\right)=(1-R) \pi_{1}+R\left(\pi-\pi_{0}\right) \\
& y_{G}=\pi_{0}+(1-R)\left(\pi-\pi_{0}-\pi_{1}\right)=R \pi_{0}+(1-R)\left(\pi-\pi_{1}\right)
\end{aligned}
$$

$y_{C}=$ retained profits; $y_{G}=$ Profits that enterprise to the government; $\pi_{0}=$ Government's fixed income; $\pi_{1}=$ enterprise's fixed income; $R=$ the ratio of profit to total profit beyond the contract. So in the contract responsibility enterprise, the process of Pareto's effective solution is as follows:

$$
\begin{aligned}
& \operatorname{Max}(1-R) \pi(\gamma, \alpha) \\
& \text { s.t.R } \pi(\gamma, \alpha)-C(\gamma) \geq \underline{U}
\end{aligned}
$$

(4) and (5) the Lagrange equation is as follows:

$$
L(\pi(\gamma, \alpha), \lambda)=(1-R) \pi(\gamma, \alpha)+\lambda[R \pi(\gamma, \alpha)-C(\gamma)-\underline{U}]
$$

According to $\mathrm{K}-\mathrm{T}$ conditions, $\mathrm{X}$ of (6) for partial derivative:

$$
\frac{\partial L}{\partial \pi}\left(\pi(\gamma, \alpha), \lambda^{0}\right)=(1-R) \pi^{\prime}(\gamma, \alpha)+\lambda^{0} R \pi^{\prime}(\gamma, \alpha)=0
$$

Solving:

$$
\lambda^{0}=\frac{R-1}{R}
$$

According to K-T conditions, $\lambda_{0} \geq 0$ and $0 \leq R \leq 1$, so $\mathrm{R}=1$. Put $\mathrm{R}=1$ to (2) and (3). The optimal solution is obtained:

$$
\begin{aligned}
& y_{C}=\pi-\pi_{0} \\
& y_{G}=\pi_{0}
\end{aligned}
$$

From the above process, we can analyze the following conclusions:

In the contract responsibility, the government is risk averse, but the contractor's attitude to risk neutral. In this case, the optimal contract between the principal and the agent 
is: $R=1, \alpha=1$. That is to say, there is the optimal contract decision in the case that the contractor must obtain the decision and the residual value of all claims and government is given quota profit.

As the contractor is involved in the distribution of profits, they will certainly do everything possible to maximize the profit of the enterprise, so as to maximizing their own utility. But in the process of maximizing profits, they are likely to use illegal means. If it is to use legal means to enhance the enterprise's profit, not only can improve the production efficiency, but also can promote the development of the national economy. Therefore, we can see that in $20^{\text {th }} 80$ s the average annual productivity of state-owned enterprises increased by $2 \%-5 \%$. But if it is not legal means, it will make the state-owned assets serious loss, damage to the interests of the country. This is also why the country has canceled the contract responsibility system.

Based on the above two points, the government in order to prevent the opportunistic behavior of the contractor, cannot put all the decision-making power and surplus value of state-owned enterprises claim to the contractor, there must be the administrative intervention of the government, it is not possible to achieve the optimal conditions of contract relationship. This also resulted in the emergence of internal control.

\section{The Governance Model in Economic Transition Period}

Since 1992, China's economy has entered a period of transition. The 14th Party Congress to determine the target model of China's socialist market economy, the fourteen session of the Third Plenary Session of the Central Committee also proposed China's SOE reform goal is to establish a modern enterprise system. After that, the country set off the climax of the establishment of modern enterprise system. The governance model of the state-owned enterprise has the characteristics of the continuous improvement of the enterprise system.

\section{The General Situation}

"Decentralization and interest concession" "Substitution of tax payment for profit delivery" and other measures although to a certain extent, to mobilize the enthusiasm of managers and employees, but does not solve the problems of state-owned enterprises fundamentally. The government is aware of only relying on temporary means of decentralization is not a cure, the reform of state-owned enterprises is not only the problem of converting an operating mechanism, but to proceed from the basic system. Therefore, the reform of state-owned enterprises is from the policy adjustment to the system. The specific contents of the reform mainly include: the transformation of enterprise management mechanism, further emancipate and develop the productive forces of state-owned enterprises; the establishment of enterprise legal person property rights, gradually establish the state-owned assets management system; gradually change the role of government and enterprises, enterprises become independent business entities, rather than the government's subsidiary bodies; improve the internal system of state-owned enterprises, and gradually establish a standardized, scientific system of state-owned enterprises, the formation of mutual constraints, and clear responsibilities of internal mechanism. During this period, the governance model of the state-owned enterprises has changed correspondingly, as follows:

There are changes of property right system in governance mode. In the stage of "decentralization and interest concession", state-owned enterprises are given the rights to claim and control of residual value, but they do not get all of the property rights, and the 
restriction mechanism of property right system is not established. At this stage, the state gradually establish a complete modern enterprise system, so that state-owned enterprises have all the property rights, state-owned enterprises to become an independent enterprise legal person, has a full operational decision-making power, bear the corresponding legal responsibility. There is a fundamental change compared to the past, because state-owned enterprises are really out of the subsidiary status of the government, and the incentive and restraint of state-owned enterprises are realized from two aspects of management mechanism and legal system.

There are changes of incentive and restraint system of the managers in governance. In the previous stage, the incentive of state-owned enterprises is mainly through the wages and business performance of the company to carry out the way, this way is also true in a certain period of time to mobilize the enthusiasm of operators. But misappropriation of state assets and other acts is leading to the loss of state assets. This period of reform through the establishment of a sound corporate governance structure, effective management of state-owned enterprises through the incentive and restraint mechanism of the corresponding hand, effective incentive for managers, on the other hand, to a certain extent to prevent misappropriation of state assets and other acts occurred.

\section{Analysis Based on Principal-Agent Theory}

This time, the principal-agent relationship has changed, but the problem still exists. Although the reform has brought about the improvement of the production efficiency of the state-owned enterprises, the problem of "insider control" is still serious, which leads to the loss of national interests. Although the government as the principal is necessary to supervise the state-owned enterprises, this supervision has a strong administrative color, leading to the state-owned enterprises are too many, the lack of energy.

\section{The Principal-Agent Relationship in Economic Transition Period}

The types of state-owned enterprises are more and more, the paper mainly takes the central enterprises as an example, to carry out the analysis of the principal-agent relationship. The state has made a reform in the principal-agent relationship, which is the establishment of the state owned assets supervision and Administration Commission (SASAC) compared to the contract responsibility system. To some extent, the establishment of the SASAC has solved the problem of the absence of the principal of the state-owned enterprises that is entrusted by the government, the exercise of the ownership of state-owned assets. SASAC is actually the principal of the central business, playing the role of major shareholder. However, the SASAC and the general shareholders have different nature, with the following characteristics:

First, SASAC is no real sense of the separation of government and enterprise that is with administrative color. Therefore, the SASAC in dealing with the problem still has the dual functions of economic and administrative.

Second, SASAC as a principal, but no right to have residual value of the enterprise, their income is not directly linked to the income of the enterprise, so they lack the original motivation to pursue profits.

Last, SASAC has an important responsibility to monitor the behavior of state-owned enterprises, but compared with the high cost of supervision, they cannot profit from the supervision of the behavior, so it has weakened the motivation of their supervision. 


\section{Incentive-Cons train Mechanism in Contract Responsibility System}

The agent's view to risk is two possibilities, one is to be avoided, and one is neutral. In the central enterprises, the SASAC (the principal) risk attitude is neutral. If the attitude of the agent to the risk is neutral, the agent's effort level is high; there is no moral hazard. If the attitude of the risk is to avoid, the level of effort is low. If the agent's effort level is $\gamma, \gamma^{H}$ represent a higher level of effort; $\gamma^{L}$ represent a lower level of effort, and $\gamma \in\left[\gamma^{H}, \gamma^{L}\right]$. In the case of the high level of the agent, the probability of obtaining $x_{i}$ is $p_{i}^{H}$; In the case of the low level of the agent, the probability of obtaining $x_{i}$ is $p_{i}^{L}$. Therefore, the programming function equation of the principal-agent is as follows:

$$
\begin{aligned}
& \operatorname{Max}_{\left\{w\left(x_{i}\right)\right\}_{i=(1,2 . n)}} \sum_{i=1}^{n} p_{i}^{H}\left[x_{i}-w\left(x_{i}\right)\right] \\
& \text { s.t. } \sum_{i=1}^{n} p_{i}^{H} u\left(w\left(x_{i}\right)\right)-v\left(\gamma^{H}\right) \geq \underline{U} \\
& \sum_{i=1}^{n}\left[p_{i}^{H}-p_{i}^{L}\right] u\left(w\left(x_{i}\right)\right) \geq v\left(\gamma^{H}\right)-v\left(\gamma^{L}\right)
\end{aligned}
$$

Solving:

$$
\frac{1}{u^{\prime}\left(w\left(x_{i}\right)\right)}=\lambda+\mu\left[1-\frac{p_{i}^{L}}{p_{i}^{H}}\right]
$$

According to K-T conditions can be derived $\mu \geq 0$. If $\mu=0, u^{\prime}\left(w\left(x_{i}\right)\right)$ is constant. This is not the situation of asymmetric information, so $\mu \neq 0$. Integrated above can be drawn $\mu>0$. We can know that the income of the agent is changed with the level of effort. From the formula (14), it can be seen that the higher the value of $\frac{p_{i}^{L}}{p_{i}^{H}}$, the higher the income of the agent. That is to say that the agent to get more income, we must pay more efforts. As a client, if want to have a higher level of effort, it is to improve the expected utility of the income of the agent. In other words, the more effort the agent, the higher the performance level of the enterprise, the more pay for the agency. But in the central business executives pay management approach, the central business executives have set the upper limit of wages, which is easy to make the central business people in charge of rent-seeking behavior.

\section{Conclusions}

From the above analysis, we can see that the government mode of state-owned enterprises has experienced a series of changes along with the reform and opening up. A part of the autonomy decentralization make state-owned enterprises have, but did not change the nature of the principal-agent relationship between the government and the managers of state-owned enterprises, state-owned enterprise operators is not the real meaning of "agent". The contractual responsibility system has changed the mode of the right of ownership and management of the state, trying to separate the ownership and right of management. State - 
owned enterprises are no longer the implementation of the national plan, and the transformation into the competition of the operators' participation in the market. The managers of the state-owned enterprises are involved in the distribution of the surplus profit. They are in the process of pursuing their own profit maximization, because there is no perfect restraint mechanism, so there is a huge moral hazard, leading to the loss of national assets. In the establishment of modern enterprise system stage, the reforms of state-owned enterprises are from decentralization to institutional innovation. The state owned assets supervision and Administration Commission of the State Council has been set up, which has formed a double principal-agent relationship. Although the SASAC has played a supervisory role, but due to the high cost of supervision, the supervision is not related to their income.

With the further deepening of the reform of state-owned enterprises, the government mode of state-owned enterprises will be further improved. According to the basic rules and methods of the principal-agent mechanism, the role and status of the state-owned enterprises in our country should be strengthened, which is based on the basic national conditions of our country and strengthening the governance structure of the state-owned enterprises, which is composed of the general meeting, the board of directors and the board of supervisors. To set up the appropriate incentive and restraint mechanisms, to give full play to the role of the management and supervision of the SASAC, to further stimulate the efforts of state-owned enterprise operators.

\section{References}

[1] John Hassard, Jonathan Morris, Jackie Sheehan. Journal of Organizational Change Management 2010, 5: 500-516

[2] Peng Bai, Economic Research, 2008 (2): 68-82.

[3] Xiu-ping Jiang, Ya-da Yang, Productivity Research Based on Institutional Change, 2009

(2): $139-140$

[4] Yu-wen Zhong, Finance and Trade Research, 2010 (4):8-10

[5] Li-wen Chen, Guang-ping Liu, Chen Sun, Industrial Technology Economy, 2013 (12): 147-148

[6] Lei Niu, Chinese and foreign Entrepreneurs, 2014 (29): 69 